\title{
Enhancement of Lipid Extraction from Marine Microalga, Scenedesmus Associated with High-Pressure Homogenization Process
}

\author{
Seok-Cheol Cho, ${ }^{1}$ Woon-Yong Choi, ${ }^{2}$ Sung-Ho Oh, ${ }^{2}$ Choon-Geun Lee, ${ }^{2}$ \\ Yong-Chang Seo, ${ }^{2}$ Ji-Seon Kim, ${ }^{2}$ Chi-Ho Song, ${ }^{2}$ Ga-Vin Kim, ${ }^{3}$ Shin-Young Lee, ${ }^{3}$ \\ Do-Hyung Kang, ${ }^{4}$ and Hyeon-Yong Lee ${ }^{5}$ \\ ${ }^{1}$ Department of Food Nutrition, Seowon University, Cheongju 361-742, Republic of Korea \\ ${ }^{2}$ Department of Biomedical Materials Engineering, Kangwon National University, Chuncheon 200-701, Republic of Korea \\ ${ }^{3}$ Department of Bioengineering and Technology, Kangwon National University, Chuncheon 200-701, Republic of Korea \\ ${ }^{4}$ Korea Institute of Ocean Science \& Technology, Ansan P.O. Box 29, Seoul 426-744, Republic of Korea \\ ${ }^{5}$ Department of Teaics, Seowon University, Cheongju 361-742, Republic of Korea
}

Correspondence should be addressed to Hyeon-Yong Lee, hyeonl@seowon.ac.kr

Received 13 March 2012; Accepted 22 May 2012

Academic Editor: Chiu-Chung Young

Copyright ( $) 2012$ Seok-Cheol Cho et al. This is an open access article distributed under the Creative Commons Attribution License, which permits unrestricted use, distribution, and reproduction in any medium, provided the original work is properly cited.

\begin{abstract}
Marine microalga, Scenedesmus sp., which is known to be suitable for biodiesel production because of its high lipid content, was subjected to the conventional Folch method of lipid extraction combined with high-pressure homogenization pretreatment process at $1200 \mathrm{psi}$ and $35^{\circ} \mathrm{C}$. Algal lipid yield was about $24.9 \%$ through this process, whereas only $19.8 \%$ lipid can be obtained by following a conventional lipid extraction procedure using the solvent, chloroform: methanol $(2: 1, \mathrm{v} / \mathrm{v})$. Present approach requires 30 min process time and a moderate working temperature of $35^{\circ} \mathrm{C}$ as compared to the conventional extraction method which usually requires $>5 \mathrm{hrs}$ and $65^{\circ} \mathrm{C}$ temperature. It was found that this combined extraction process followed second-order reaction kinetics, which means most of the cellular lipids were extracted during initial periods of extraction, mostly within 30 min. In contrast, during the conventional extraction process, the cellular lipids were slowly and continuously extracted for $>5$ hrs by following first-order kinetics. Confocal and scanning electron microscopy revealed altered texture of algal biomass pretreated with highpressure homogenization. These results clearly demonstrate that the Folch method coupled with high-pressure homogenization pretreatment can easily destruct the rigid cell walls of microalgae and release the intact lipids, with minimized extraction time and temperature, both of which are essential for maintaining good quality of the lipids for biodiesel production.
\end{abstract}

\section{Introduction}

Biodiesel production from microalgae mainly consists of biomass production, lipid extraction, and transesterification of extracted lipids $[1,2]$. Among these processes, lipid extraction is the most costly, and can create a bottleneck of biodiesel production. Among the many types of microalga, Scenedesmus sp., marine green alga is known to be an excellent source of biodiesel due to its high lipid content (16 40\%) [3]. However, research on lipid extractions from Scenedesmus sp. is insufficient compared to those from other microalgae, even though expeller/press method, solvent oil method, supercritical fluid extraction method, enzyme preparation, osmotic shock, ultrasonic assisted extraction, and others have been used thus far for lipid extraction from various biomass resources [1].

In general, solvent extraction method is most commonly used as it has been well studied. However, it can be used without any safety hazard and is most often used for the lipid extraction of animal tissues [4-6]. Microalgae have rigid cell walls, which work against the rate controlling step of solvent extraction resulting in difficulties in effective extraction [7]. Generally, it is known that the study on extraction dynamics and phase equilibrium is essential to 


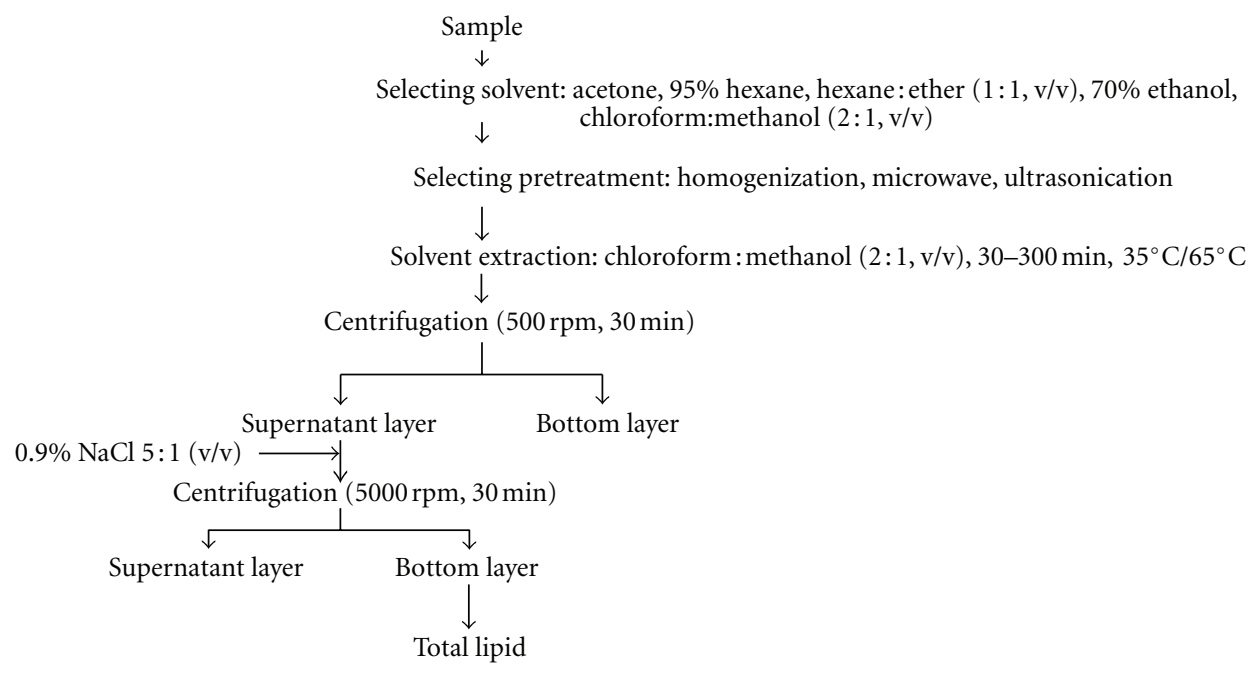

FIGURE 1: A flow diagram of lipid extraction from Scenedesmus sp.

the economic design of extraction devices and application of bioprocesses [8]. Specifically in the case of having a strong cell wall causing a slow extraction rate, it is necessary to study the extraction dynamic behavior that would provide information on the extraction mechanism in order to improve extraction efficiency. Therefore, the aim of this study was to introduce an effective extraction solvent method combined with a pretreatment step, which would enhance the extraction yield and rate of neutral lipids for biodiesel production from Scenedesmus sp. by considering their combination and kinetic analysis.

\section{Materials and Methods}

2.1. Sample Preparation. Scenedesmus sp. (Korea Ocean Research and Development Institute, Korea) was grown in IMK medium consisting of $200 \mathrm{mg} \mathrm{NaNO}, 1.4 \mathrm{mg} \mathrm{Na} \mathrm{NPO}_{4}$, $5 \mathrm{mg} \mathrm{K}_{2} \mathrm{HPO}_{4}, 2.68 \mathrm{mg} \mathrm{NH}{ }_{4} \mathrm{Cl}, 5.2 \mathrm{mg}$ Fe-EDTA, $0.332 \mathrm{mg}$ Mn-EDTA, $37.2 \mathrm{mg} \mathrm{Na}$-EDTA, $0.023 \mathrm{mg} \mathrm{ZnSO}_{4} \cdot 7 \mathrm{H}_{2} \mathrm{O}$, $0.014 \mathrm{mg} \quad \mathrm{CoSO}_{4} \cdot 7 \mathrm{H}_{2} \mathrm{O}, 7.3 \mu \mathrm{g} \quad \mathrm{Na}_{2} \mathrm{MoO}_{4} \cdot 2 \mathrm{H}_{2} \mathrm{O}, \quad 2.5 \mu \mathrm{g}$ $\mathrm{CuSO}_{4} \cdot 5 \mathrm{H}_{2} \mathrm{O}, 0.2 \mathrm{mg}$ Thiamine- $\mathrm{HCl}, 1.5 \mu \mathrm{g}$ biotin, $1.5 \mu \mathrm{g}$ vitamin $\mathrm{B} 12$, and $0.18 \mathrm{mg} \mathrm{MnCl}_{2} \cdot 4 \mathrm{H}_{2} \mathrm{O}$ dissolved in a liter of artificial seawater and harvested by a centrifuge at $3000 \mathrm{rpm}$ for $10 \mathrm{~min}$ [9]. The samples were freeze-dried and stored at $4^{\circ} \mathrm{C}$ before use.

\subsection{Lipid Extractions under Various Extraction Conditions.} As shown in Figure 1 (a flow diagram of algal lipid extraction), to select the best extraction solvent, we used five of the most common lipid extraction solvents such as, acetone, 95\% hexane, hexane : ether $(1: 1, \mathrm{v} / \mathrm{v}), 70 \%$ ethanol, and chloroform: methanol $(2: 1, \mathrm{v} / \mathrm{v})$. Detailed extraction procedures were as follows: at first, $1 \mathrm{~g}$ of the freeze-dried sample was extracted with $50 \mathrm{~mL}$ of each solvent in a $1 \mathrm{~L}$ batch type extractor at room temperature $(400 \mathrm{rpm}$, $24 \mathrm{hrs})$. Then, the extracts were filtered through a filter paper (Watman, no. 5), and the filtrates and residual algal lipid droplets were stained with $10 \%$ Nile red. The sample was observed under a fluorescence microscope (Eclipe 50i, Nikon, Japan) and a confocal laser microscope (FV300, Olympus, Japan) [9]. As a control, the dried biomass without any solvent treatment was stained with Nile red to show the intact cellular lipids.

After selecting chloroform: methanol $(2: 1 \mathrm{v} / \mathrm{v})$ as an optimal extraction solvent, $1 \mathrm{~g}$ of the sample was treated with $30 \mathrm{ml}$ of solvent $\left(500 \mathrm{rpm}, 12 \mathrm{hrs}\right.$ at $\left.65^{\circ} \mathrm{C}\right)$. Then, the extracts were centrifuged at $5000 \mathrm{rpm}$ for $30 \mathrm{~min}$, and the supernatant was added to five times volume of $0.9 \% \mathrm{NaCl}$ solution. The bottom layer of the extracts was dried and the weight of total lipids was measured for estimating extraction yields.

To evaluate the performance of microwave, ultrasonification, and homogenization methods, each pretreatment process was applied before being extracted with chloroform : methanol $(2: 1, \mathrm{v} / \mathrm{v})$ : For the microwave pretreatment, the sample was put in a microwave oven (Mr-216 mr, $1200 \mathrm{~W}$, Korea) at a frequency of $2450 \mathrm{MHz}$ for $5 \mathrm{~min}$; for the ultrasonification pretreatment, an ultrasonicator (Bransonic 5210, USA) was used on the solvent at $47 \mathrm{kHz}$ for $10 \mathrm{~min}$; for the homogenization pretreatment, a highpressure homogenizer (Micronox Inc. Korea) was used as shown in Figure 2, where $70 \mu \mathrm{m}$ diameter Y-type diamond nozzle was installed in a $1 \mathrm{~m}$ long stainless steel pipe at room temperature. The sample was passed through a nozzle at 1200 psi pressure. The average size of the sample was reduced to $1-4 \mu \mathrm{m}$ by the shear stress when it was released externally by cavitation [10]. Samples obtained after each pretreatment processes were extracted independently by following the method described in the previous paragraph except that the temperature was reduced to $35^{\circ} \mathrm{C}$. As a control, nonpretreated sample was directly used for lipid extraction, exactly as given in the previous paragraph.

Before and after extracting the pretreated samples with the solvent, the surface textures were observed by field emission scanning electron microscope (FE-SEM: Hitachi S4300, Japan) at 200 5000x magnified mode. 


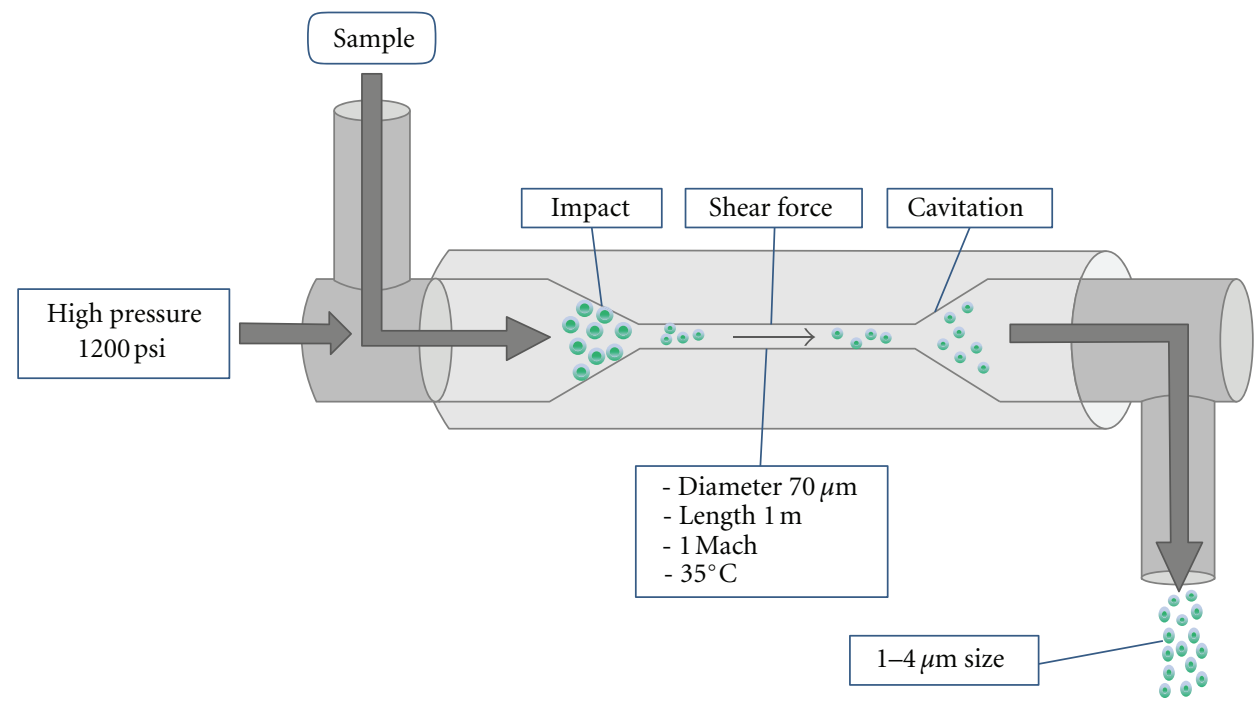

FIgURE 2: A schematic diagram of high-pressure homogenizer employed for pretreatment of algal biomass.

2.3. Kinetic Analysis of Lipid Extraction. To fit the kinetic models to lipid extraction process, the following first-order or second-order rate equations were employed since these models were widely applied for the analysis of dissolution and leaching within inhomogeneous liquid-solid systems [11].

First-order equation:

$$
\log \left(C_{s}-C_{t}\right)=\log C_{s}-\left(\frac{k_{1}}{2.303}\right) \times t,
$$

second-order equation:

$$
\frac{t}{C_{t}}=\frac{1}{k_{2} C_{s}^{2}}+\left(\frac{1}{C_{s}}\right) \times t
$$

Here, $C_{s}$ and $C_{t}$ represent the concentrations of extracted lipids and total cellular lipids, respectively, at an arbitrary time $t ; k_{1}$ and $k_{2}$ represent first-order and second-order rate constants, respectively.

\section{Results and Discussion}

3.1. Comparative Analysis of Solvent Condition on the Lipid Extraction. Figure 3 illustrates the Nile red stained cellular lipid droplets after being extracted by five different extraction solvents including the control; no treatment (a), acetone (b), 95\% hexane (c), hexane: ether $(1: 1, \mathrm{v} / \mathrm{v})$ (d), 70\% ethanol (e), and chloroform: methanol $(2: 1, v / v)(f)$. When compared to the control (a) with many yellow triglycerides (neutral lipids), a large proportion of red colored polar lipids were observed in the residue after being extracted by solvent (f), which suggested that solvent (f), unlike the other solvents, extracted most of neutral lipids from the biomass and left only polar lipids in the residue. By using this solvent, approximately $15 \%(\mathrm{w} / \mathrm{w})$ of extraction yield was obtained, as compared to $1.3 \%, 2.1 \%, 4.5 \%$, and $11.1 \%(\mathrm{w} / \mathrm{w})$ lipid obtained by using acetone, $95 \%$ hexane,

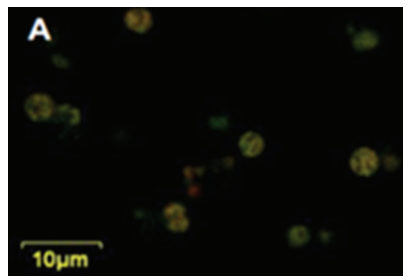

(a)

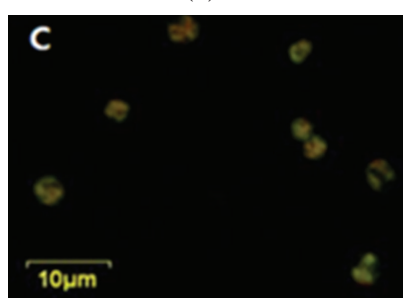

(c)

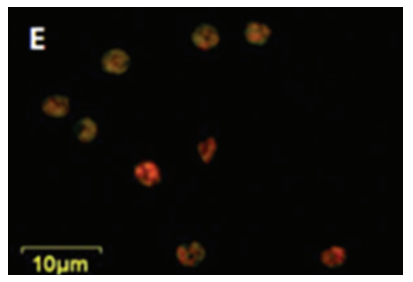

(e)

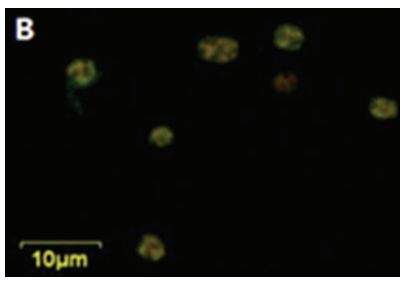

(b)

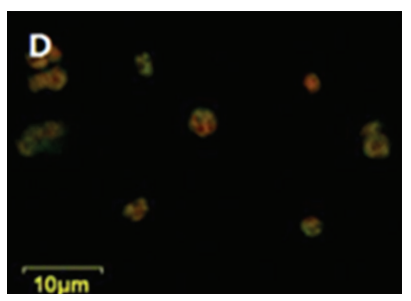

(d)

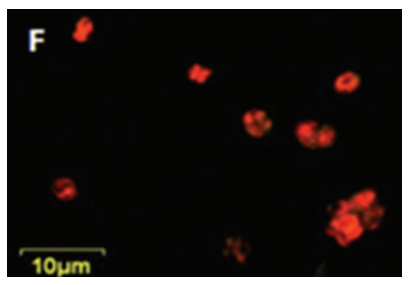

(f)
Figure 3: Comparison of the confocal laser microscopic images of Scenedesmus sp. illustrates the Nile red stained residual cellular lipid droplets after being extracted by five different extraction solvents including the control; (a) control (not extracted with any solvent), (b) acetone, (c) 95\% hexane, (d) hexane: ether (1:1,v/v), (e) 70\% ethanol, and (f) chloroform : methanol $(2: 1, \mathrm{v} / \mathrm{v})$.

hexane: ether $(1: 1, \mathrm{v} / \mathrm{v})$, and $70 \%$ ethanol, respectively. It implies that the most proper extraction solvent for this alga would be chloroform: methanol $(2: 1, \mathrm{v} / \mathrm{v})$, which could also be supported by the results that show mixing two or three solvents would be better for lipid extraction $[5,12]$. 


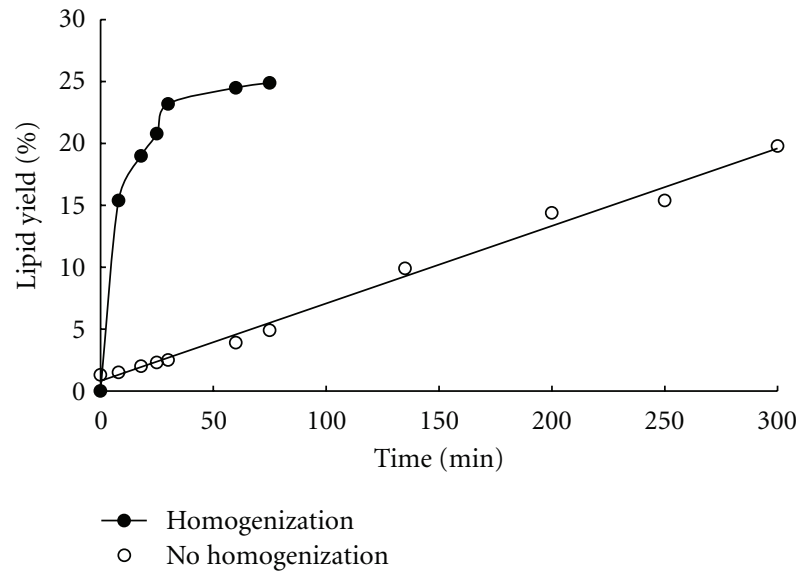

FIgURE 4: Comparison of the lipid extraction profile with $(\bullet)$ and without $(\bigcirc)$ homogenization as a pretreatment extracted with chloroform : methanol $(2: 1, \mathrm{v} / \mathrm{v})$ solvent. Extraction yield was calculated by the weight ratio of the extracted lipids to the total dried biomass.

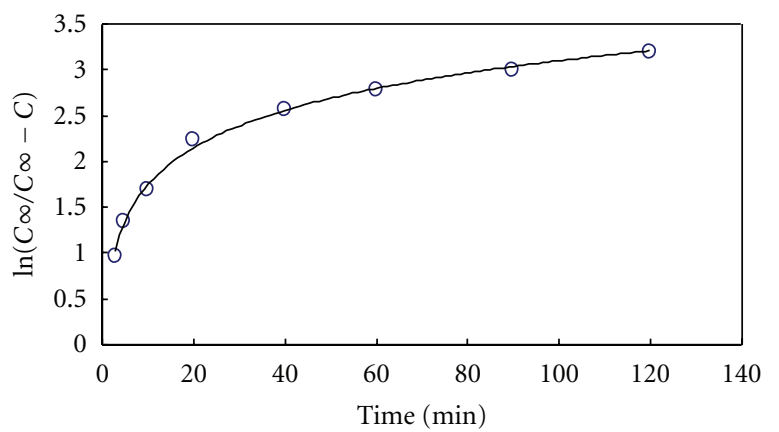

(a)

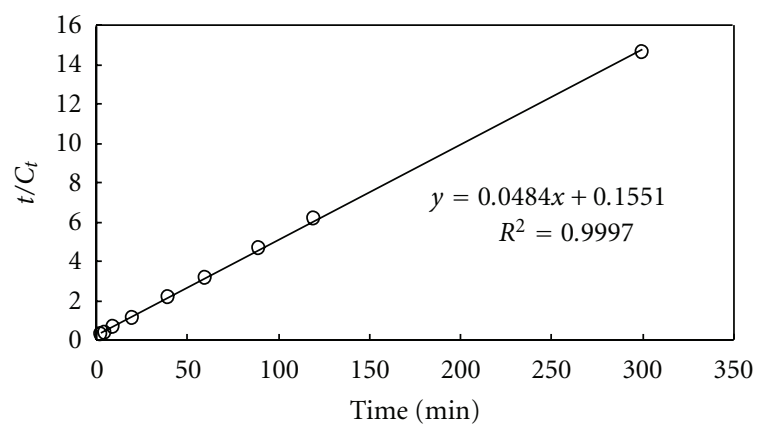

(b)

FIgURE 5: Result of first-order (a) and second-order (b) plots of lipid extraction from Scenedesmus sp. with homogenization pretreatment.

\subsection{Effect of High-Pressure Homogenization on Cellular Lipid} Extraction. Figure 4 compares the lipid extraction patterns from two different processes: conventional Folch extraction at $65^{\circ} \mathrm{C}$ versus combined extraction at $35^{\circ} \mathrm{C}$. For combined extraction process, the algal biomass was passed through a high-pressure homogenizer at 1200 psi, then extracted with chloroform: methanol $(2: 1, \mathrm{v} / \mathrm{v})$ at $35^{\circ} \mathrm{C}$. Because, in general, it was known that high-pressure homogenization could effectively disrupt the cell membrane at room temperature due to high shear stress application inside the orifice and large pressure drop at the outlet [13]. It was found that the conventional extraction process showed a first-order reaction release pattern while the combined process followed second-order kinetics possibly because of easy disruption of relatively rigid algal cell membranes [14]. It was observed that during the conventional extraction process the external mass transfer resistance was important since generally the dissolution of lipids by the solvent and the external mass transfer occur in the opposite direction in the extraction processes, including the penetration of outer cell walls by the solvent [15]. It was also interesting that two steps were observed in extracting the lipids during the conventional extraction process: the initial slow stage for the first $1 \mathrm{hr}$ and the later faster stage after $2-5 \mathrm{hrs}$. This implies that the initial step worked as the rate-limiting stage for this process. Compared with the case of no pretreatment process, the combined extraction method showed the typical second-order reaction kinetics which consists of two consecutive processes. The first process is a fast elution process for the first $30 \mathrm{~min}$ followed by a slower process in which after the elution, the internal diffusion, and the external diffusion from the liquid of the solute occur. Such phenomena occurred because when the biomass was exposed to fresh solvent, the lipid on its surface was solubilized and extracted rapidly. While at the initial stage of extraction, as the concentration of lipid was low in the solvent layer, the diffusion from the solid to the liquid occurred due to the mass transfer effect. As shown in the Figure 4, when a reaction time of $30 \mathrm{~min}$ was elapsed, a balanced state reaction was observed for the homogenized sample with a lipid extraction yield of $24.90 \%(\mathrm{w} / \mathrm{w})$, which was slightly higher than the yield $(19.80 \%, w / w)$ obtained for nonhomogenized sample after extended treatment for about $5 \mathrm{hrs}$. It was found that this combined extraction process followed second-order reaction kinetics, which means that most of the cellular lipids were extracted for the first periods of extraction, probably within $30 \mathrm{~min}$. In contrast, during the conventional extraction process, the cellular lipids were slowly and continuously extracted for $<5 \mathrm{hrs}$ by following first-order kinetics. The results clearly showed that the destruction of cells through high-pressure homogenization and the combined solvent extraction method could help to increase the lipid extraction during the same time. In Figure 4, the extraction pattern was determined to follow second-order reaction kinetics. To confirm the reaction kinetics, the homogenization pretreatment data given in Figure 4 were fitted to (1) and (2) given in materials and methods. Based on Figure 5(b), the data fit well to the second-order kinetic (2) with a 0.9997 linear regression coefficient while the result did not linearly fit to the first-order (1) in Figure 5(a). In Figure 5(b), the rate constant of the second-order rate equations based on lipid extraction kinetics for the homogenization treatment was estimated to be $0.0053 \mathrm{~min}^{-1}$, which was much higher than $0.0000527 \mathrm{~min}^{-1}$ of extracting lipid from macroalga, Ulva lactuca which shows first-order kinetics [16]. This result clearly implies that the destruction of cells by applying the high-pressure could efficiently extract the lipids 


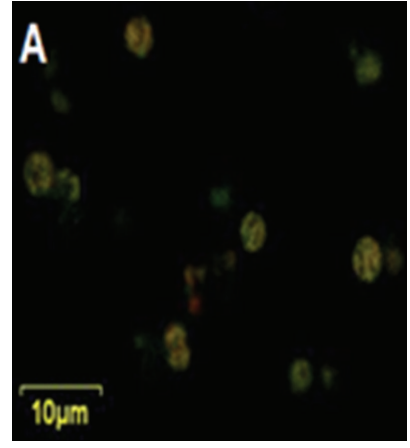

(a)

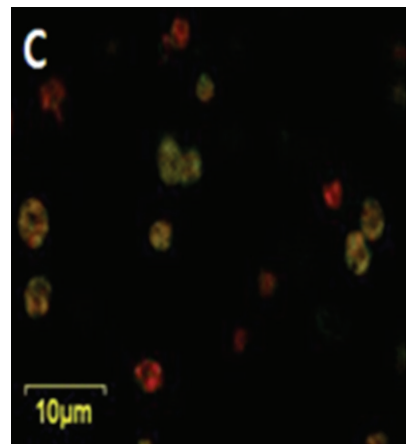

(c)

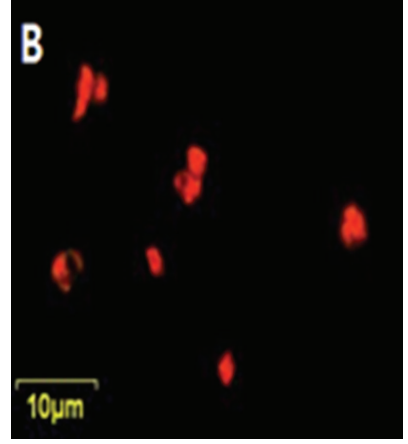

(b)

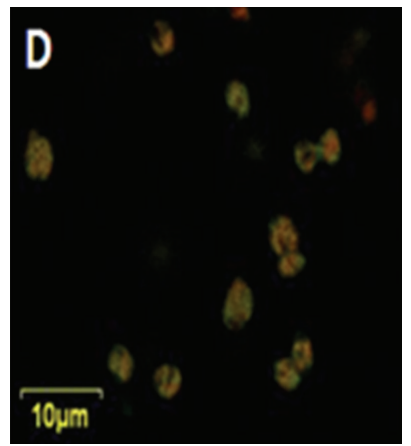

(d)
FIgURE 6: Comparison of confocal laser micrograph of Scenedesmus sp. stained with Nile red showing residual cellular lipid droplets; (a) control (only solvent extraction without any pretreatment), (b) solvent extraction with homogenization pretreatment, (c) solvent extraction with microwave pretreatment, and (d) solvent extraction with ultrasonification pretreatment.

with a significant minimization in the extraction time ( $\sim 9$ times) as compared to nonhomogenized sample subjected to conventional extraction process.

\subsection{Comparative Analysis of Lipid Extraction Patterns Accord-} ing to Pretreatment Processes. From the above results, it was found that the extraction yield could be significantly increased by a high-pressure pretreatment process because the external mass transfer acted as the primary resistance due to the rigid structure of the algal cell walls [17]. Figure 6 shows characteristics of the residual cellular-lipid droplets in several pretreatment conditions. In control (a), most of the lipids in the residue remained as the yellow-colored droplets with the least extractions of neutral lipids. On the contrary, for others, after treating with any pretreatment, more neutral lipids were extracted even though there was an observable difference among the treatment conditions. As expected, the homogenization pretreatment process (b) maintained the best performance on extracting neutral lipids from the biomass compared to the processes such as microwave (c) and ultrasonic (d) pretreatments, showing that only polar lipids were left behind in the homogenized residue. After completion of $30 \mathrm{~min}$. extraction time, a lipid yield of about $15.6 \%$ and $11.5 \%$ was obtained for the sample pretreated with microwave and ultrasonication,
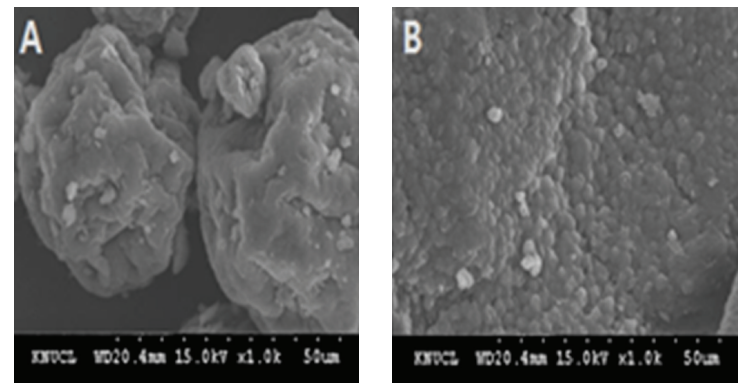

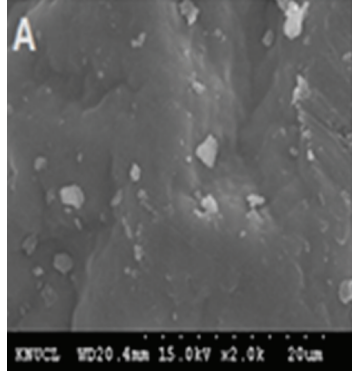

(a)
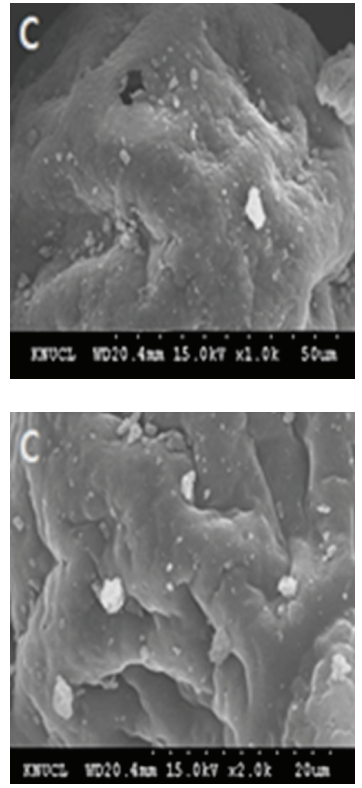

(c)

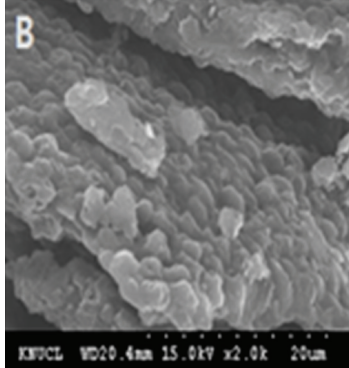

(b)
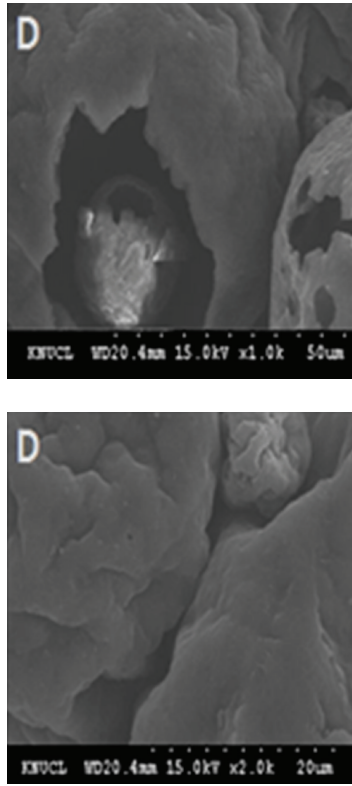

(d)
FIGURE 7: Scanning electron micrograph (SEM) of Scenedesmus sp. after several extraction processes (top: 1000x, bottom: 2000x); (a) control (only solvent extraction without any pretreatment), (b) solvent extraction with homogenization pretreatment, (c) solvent extraction with microwave pretreatment, and (d) solvent extraction with ultrasonification pretreatment.

respectively, which was relatively lesser as compared to the yield ( $\sim 25 \%)$, obtained for the sample pretreated with highpressure homogenization. These results indicate that the extraction of neutral lipid can be significantly increased through the efficient destruction of cell walls by properly preconditioning the samples. To confirm this hypothesis, the surface textures of the samples were investigated by using SEM in Figure 7. For the case of homogenization pretreatment (b), many structures were spherically formed 
with about a $5 \mu \mathrm{m}$ diameter, which was seldom observed in other samples such as microwave pretreatment (c) and ultrasonification pretreatment (d) whose shapes were similar to control (a). Based on this result, it was understood that due to high-pressure homogenization preconditioning, the large sizes of spherical masses (a) of the nonpreconditioned biomass were broken down into very small individual shapes, which resulted in high extraction of neutral lipids with less damage than other processes. This may also have occurred since at the initial stage of solvent extraction, the individual samples were disintegrated due to the highly increased surface area leading to the improved extraction yield and also considering that the extraction yield increases dramatically during the solvent extraction.

\section{Conclusion}

The high-pressure homogenization pretreatment-coupled Folch method described in this study is found efficient than conventional lipid extraction method. This process works greatly at moderate temperature. The efficiency of this process was confirmed by analyzing residual algal cellular lipids using Nile red dye. By kinetic analysis, it was found that this combined process followed second-order extraction kinetics showing that most of the lipids were extracted during the first period of extraction. While most solvent extraction methods follow first-order reaction kinetics where the lipids are continuously extracted as the extraction time is increased, which results in a longer processing time. From confocal laser images and scanning electron microscope observation, it can be seen that this could be due to the effective destruction of the rigid cell walls at high-pressure homogenization. These results imply that this simple and efficient process could be employed to economically obtain mass amounts of good quality lipids from marine resources.

\section{Acknowledgments}

This work was supported by Human Resources Development (2008-N-BL-HM-E-06) of the Korea Institute of Energy Technology Evaluation and Planning (KETEP) grant funded by the Korea Government Ministry of Knowledge Economy. This study was carried out with the support of Korea Institute of Ocean Science \& Technology (Project No. PE98592), Korea.

\section{References}

[1] S. Amin, "Review on biofuel oil and gas production processes from microalgae," Energy Conversion and Management, vol. 50, no. 7, pp. 1834-1840, 2009.

[2] A. B. M. S. Hossain, A. Salleh, A. N. Boyce, P. Chowdhury, and M. Naqiuddin, "Biodiesel fuel production from algae as renewable energy," American Journal of Biochemistry and Biotechnology, vol. 4, no. 3, pp. 250-254, 2008.

[3] S. Mandal and N. Mallick, "Microalga Scenedesmus obliquus as a potential source for biodiesel production," Applied Microbiology and Biotechnology, vol. 84, no. 2, pp. 281-291, 2009.
[4] S. Sayyar, Z. Z. Abidin, R. Yunus, and A. Muhammad, "Extraction of oil from Jatropha seeds-optimization and kinetics," American Journal of Applied Sciences, vol. 6, no. 7, pp. 1390-1395, 2009.

[5] J. Folch, M. Lees, and G. H. Sloane-Stanley, "A simple method for the isolation and purification of total lipides from animal tissues," The Journal of Biological Chemistry, vol. 226, no. 1, pp. 497-509, 1957.

[6] E. G. Bligh and W. J. Dyer, "A rapid method of total lipid extraction and purification," Canadian Journal of Biochemistry and Physiology, vol. 37, no. 8, pp. 911-917, 1959.

[7] K. H. Wiltshire, M. Boersma, A. Möller, and H. Buhtz, "Extraction of pigments and fatty acids from the green alga Scenedesmus obliquus (Chlorophyceae)," Aquatic Ecology, vol. 34, no. 2, pp. 119-126, 2000.

[8] T. H. Walker, H. D. Cochran, and G. J. Hulbert, "Supercritical carbon dioxide extraction of lipids from Pythium irregulare," Journal of the American Oil Chemists' Society, vol. 76, no. 5, pp. 595-602, 1999.

[9] T. Matsunaga, M. Matsumoto, Y. Maeda, H. Sugiyama, R. Sato, and T. Tanaka, "Characterization of marine microalga, Scenedesmus sp. strain JPCC GA0024 toward biofuel production," Biotechnology Letters, vol. 31, no. 9, pp. 1367-1372, 2009.

[10] W. Y. Choi, H. Y. Lee, J. H. Ahn et al., "Enhancement of sacchaarification yield of Ulva pertusa Kjellman by highpressure homogenization process for bioethanol production," Korean Society for Biotechnology and Bioengineering Journal, vol. 26, no. 1, pp. 400-406, 2011.

[11] R. L. Rakotondramasy, J. L. Havet, C. Porte, and H. Fauduet, "Solid-liquid extraction of protopine from Fumaria officinalis L.-analysis determination, kinetic reaction and model building," Separation and Purification Technology, vol. 54, no. 2, pp. 253-261, 2007.

[12] O. Grimal, D. P. Masson, L. Bertrand, and A. Yelon, "Evidence of weak phonon coupling to the $\mathrm{Si}-\mathrm{H}$ stretching modes in aSi:H," Physical Review B, vol. 49, no. 15, pp. 10242-10247, 1994.

[13] Y. Chisti and M. Moo-Young, "Review: disruption of microbial cells for intracellular products," Enzyme and Microbial Technology, vol. 8, no. 4, pp. 194-204, 1986.

[14] C. Ru'an, T. Jun, G. Hong et al., "Kinetics of leaching flavonoids from pueraria lobata with ethanol," Chinese Journal of Chemical Engineering, vol. 14, no. 3, pp. 402-406, 2006.

[15] M. Ly, A. Margaritis, and B. Jajuee, "Effect of solvent concentration on the extraction kinetics and diffusivity of Cyclosporin A in the fungus Tolypocladium inflatum," Biotechnology and Bioengineering, vol. 96, no. 1, pp. 67-79, 2007.

[16] T. Suganya and S. Renganathan, "Optimization and kinetic studies on algal oil extraction from marine microalgae Ulva lactuca," Bioresource Technology, vol. 107, pp. 319-326, 2012.

[17] S. H. Oh, J. G. Han, J. H. Ha et al., "Enhancement of immune activity of Spirulina maxima by low temperature ultrasonification extraction," Korean Journal of Food Science and Technology, vol. 41, no. 3, pp. 313-319, 2009. 

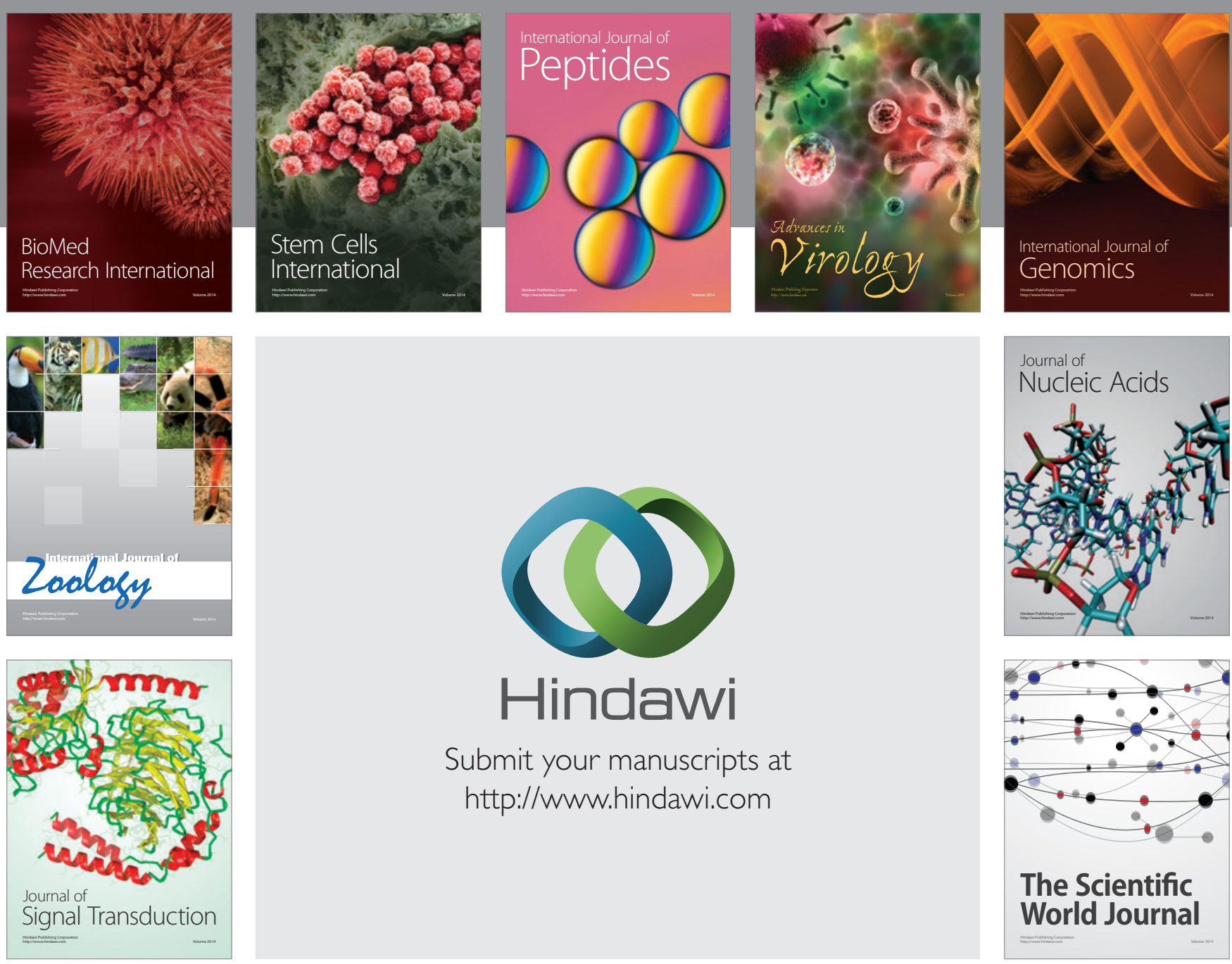

Submit your manuscripts at

http://www.hindawi.com
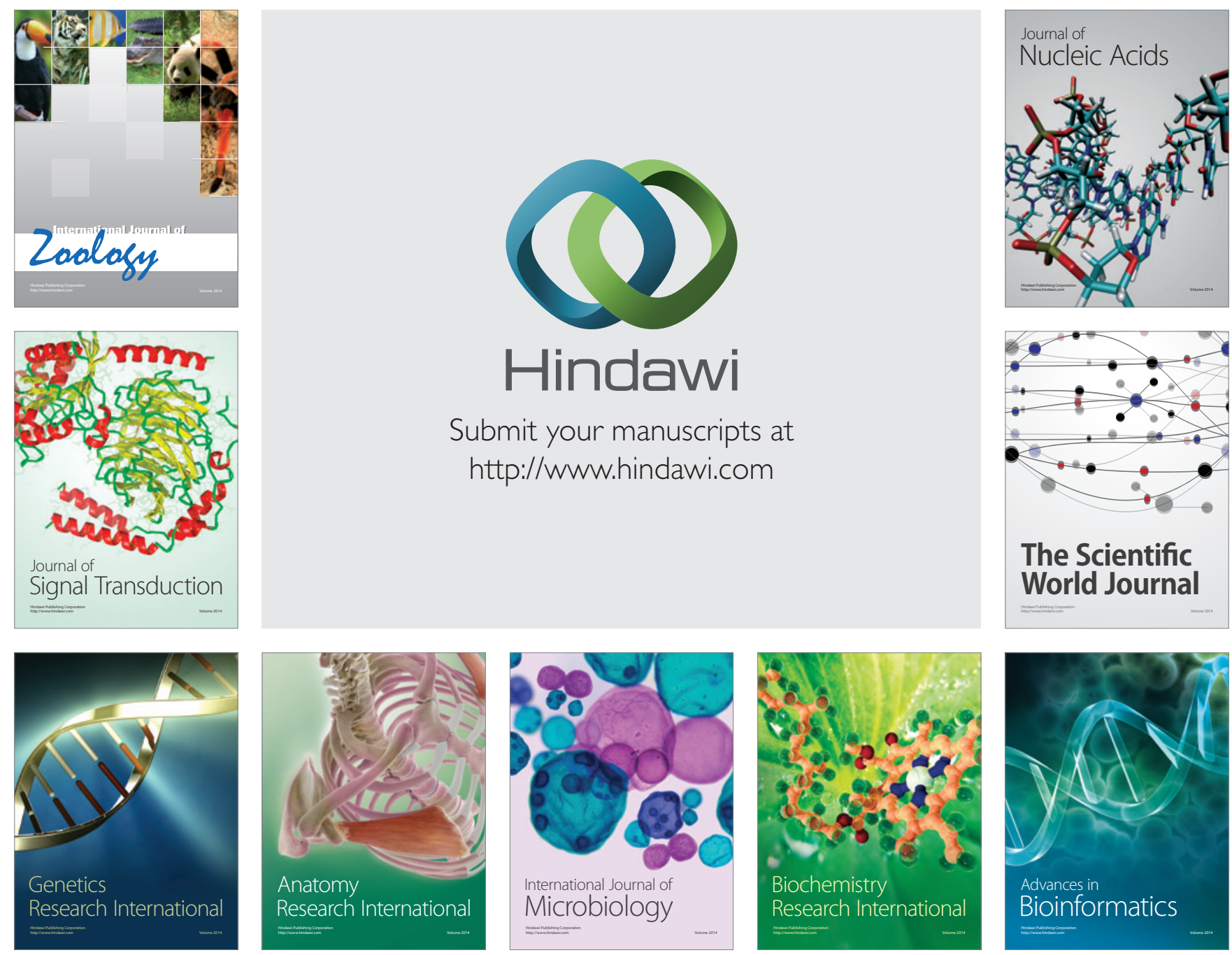

The Scientific World Journal
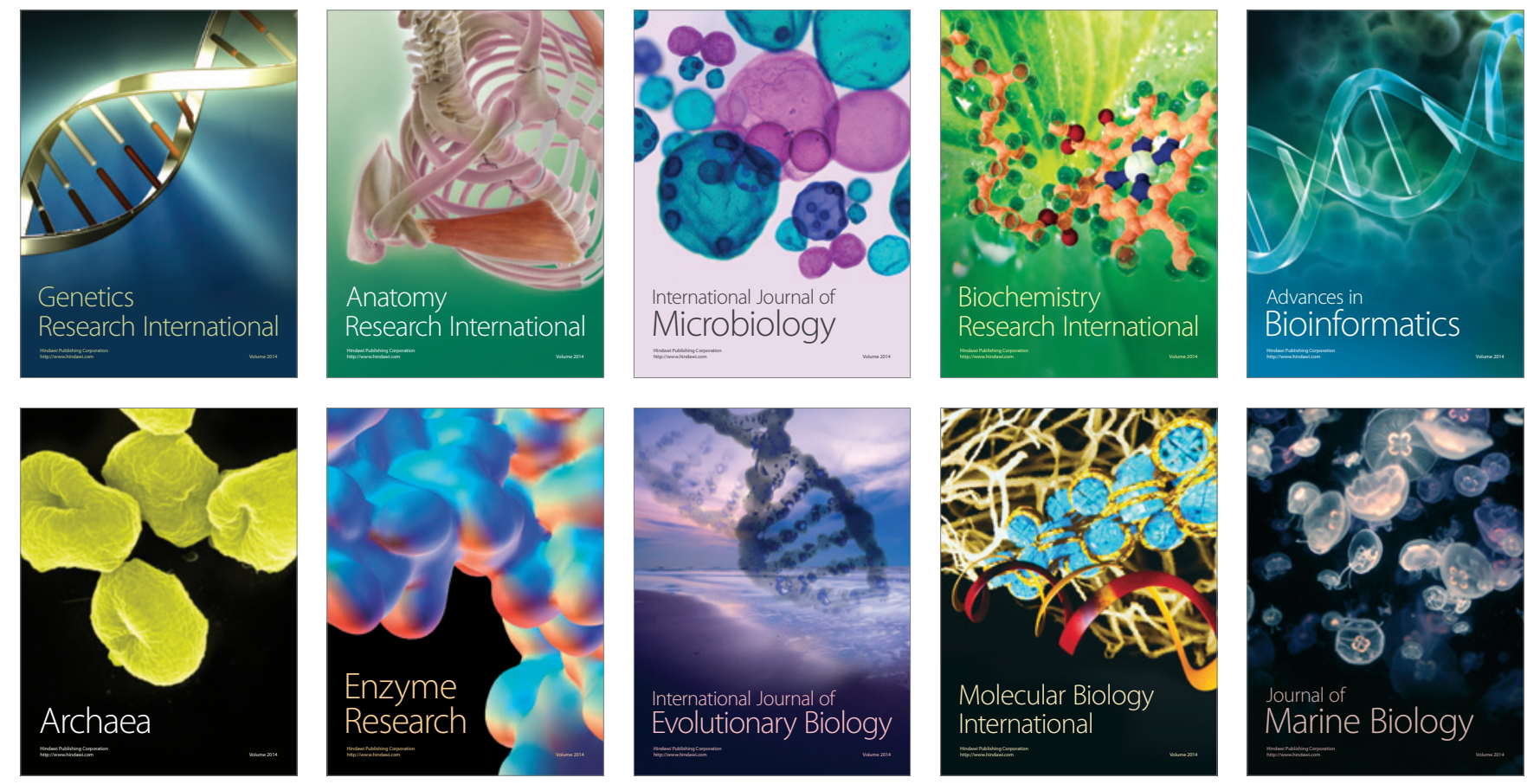